\title{
Seeking and Finding Research Collaborators: An Exploratory Study of Librarian Motivations, Strategies, and Success Rates
}

\author{
Ngoc-Yen Tran and Emily K. Chan
}

\begin{abstract}
Library and information science research is increasingly conducted in collaboration; while this phenomenon has been largely acknowledged in the profession, there is a lack of clarity on the factors that motivate librarians to seek research collaborators. This exploratory study explores librarians' motivations, strategies, and their perceived or relative success rates for finding collaborations on research projects or library initiatives. Survey results indicate that the most prevalent motivators for seeking a collaborator were to acquire expertise that one lacked, sustain research interest, and obtain a sounding board. Workplace culture, being open to collaborations, and attending conferences and meetings were the top selected strategies for finding research collaborators with the highest relative success rates.
\end{abstract}

\section{Introduction}

Library and information science (LIS) research has been increasingly conducted in collaboration, whereby the professional contributions are written by two or more authors. This phenomenon has been observed in the literature, but there is a lack of clarity on the factors that motivate librarians to seek research collaborators. Further, there is little data on the methods that librarians use to engage others in research endeavors, as well as their relative successes. This study aims to address this gap in the literature by clarifying librarians' research collaborator-seeking motivations, strategies used, and their relative successes and outcomes. The intent of this study is to provide greater context for this current phenomenon of collaborative research outputs through an examination of three lines of inquiry:

1. What motivates librarians to collaborate?

2. What methods or strategies do librarians use to find collaborators for research projects?

3. What is the relative or perceived success rate of the methods or strategies?

\section{Literature Review}

Publication co-authorship, defined as having two or more authors, is often used to identify existing research collaborations. Research across all disciplines has found dramatic increases of co-

\footnotetext{
*Ngoc-Yen Tran is Research Impact Librarian and Emily K. Chan Interim Associate Dean for Research and Scholarship at San José State University; email: yen.tran@sjsu.edu, emily.chan@sjsu.edu. @2020 Ngoc-Yen Tran and Emily K. Chan, Attribution-NonCommercial-NoDerivatives (https://creativecommons.org/licenses/by-nc-nd/4.0/) CC BY-NC-ND.
} 
authored papers, especially in the natural sciences and engineering disciplines; however, in the last decade, social sciences and health sciences disciplines have also seen growth in collaborative research output. ${ }^{1}$ Research examining co-authorship in library and information science (LIS) has also demonstrated that research collaborations are common and an increasing phenomenon among academic librarians. Content analysis of College $\mathcal{E}$ Research Libraries (CERL) from 1939 to 1994 by Gloria S. Cline and later by James L. Terry indicated that, during the five-year timespan of 1939-1944, only 4.3 percent of the total articles had a co-author; ${ }^{2}$ this percentage climbed significantly to 14.1 percent for CERL articles published between 1965 and 1969, and later to 59.5 percent for articles published between 1989 and 1994. ${ }^{3}$ Another study by Alice Harrison Bahr and Mickey Zemon of CERL and the Journal of Academic Librarianship (JAL) from 1993 to 1996 found that almost 3 out of 4 articles were co-authored. ${ }^{4}$ A more recent study of only JAL from 2004 to 2013 by Lili Luo and Margaret McKinney confirmed what the previous research had indicated - that the majority of the articles were written by two or more people (54.3\%). ${ }^{5}$

Continuation of studies using the same set of 32 journal titles and methodology but with different publication year ranges have affirmed that co-authorship among U.S. academic librarians is commonplace and growing. In their study of a broad group of library journals, the researchers found that 44.97 percent of the articles were co-authored in 1993-1997, 61.09 percent in $1998-2002,{ }^{7} 48.62$ percent in $2003-2007,{ }^{8}$ and 53.55 percent in $2008-2012 .{ }^{9}$ While there were fluctuations across different LIS journals and publication year ranges, there is indeed an upward trend and growth in academic collaborations in LIS research.

Reasons for the increase in co-authored works are numerous and extensive across disciplines. Within the body of LIS research, there are two major studies by Richard L. Hart that explore academic librarians' motivations for collaborating, which are directly relevant to the current study. In his first study, Hart surveyed Pennsylvania State University librarians, asking them to rank on a 5-point scale the importance of four possible advantages to collaboration. The Penn State librarians indicated contributions of new ideas and providing expertise that they lack as the two most important aspects for collaborating, followed by shared workload and additional publications for tenure or promotion. ${ }^{10}$ Responding to a free-text question, the Penn State librarians also stated helping younger colleagues gain research experience, greater editing quality, social interactions with colleagues, and ability to bounce ideas or enter into a new subject area as other benefits of collaborating. ${ }^{11}$

In his second study on this topic, Hart surveyed all authors of co-authored articles in $C \mathcal{E} R L$ and JAL from 1997 and 1998. In this survey, Hart asked the respondents to rank on a 10-point scale the benefits of collaborating. Those surveyed indicated that higher-quality articles, co-author expertise, and co-author ideas as the top three reasons to collaborate. ${ }^{12}$ Less important benefits were division of labor, learning from the co-author, generating additional publications for tenure and promotion, getting to know a colleague, mentoring a junior librarian, and being mentored by a senior colleague. ${ }^{13}$

While Hart's two studies indicate that the greatest motivating drivers for working collaboratively are related to the intellectual gains (such as expertise and another perspective) ${ }^{14}$ nevertheless, tenure and/or promotion considerations are represented. Hart's study on co-authored works in CERL and JAL had more than half of the respondents indicating that publishing is an important component toward receiving tenure or promotion. ${ }^{15}$ Indeed, content analysis of co-author affiliations indicate that the most productive librarians work at large research institutions where publishing may be a requirement or an important aspect 
of the institutional culture. ${ }^{16}$ Additionally, it has been observed that co-authored articles are more successful; Peter Hernon et al. compared accepted and rejected manuscripts submitted to $C \mathcal{E} R L$ and found that co-authored works had a higher rate of acceptance $(35.1 \%) .{ }^{17}$

Researchers seek and find collaborators using numerous and extensive methods. Examples of collaborator-seeking strategies include: by chance at a conference, meeting, or workplace; by intent when contacting an author after reading a publication or attending a talk; through colleagues' or personal professional networks; or through the course of performing one's job responsibilities or duties. ${ }^{18}$ In recent years, discovery tools and research networks have also been developed to help researchers look for, discover, and recommend potential collaborators. ${ }^{19}$ Within LIS, descriptions of methods by which librarians seek or locate research collaborators, the success of those methods, and the general outcomes of collaborative efforts is nonexistent in the literature. Additionally, outcomes of the collaborative efforts are not explored in LIS literature.

\section{Methodology}

The authors developed a survey questionnaire to better understand librarian co-authorship motivations, strategies, and outcomes. Using Qualtrics and its branching and skip-logic features, the authors designed a series of questions to identify if the library professional had ever, was currently, or was planning to seek a research collaborator. Respondents were asked to indicate the importance of certain motivational factors in their decisions to seek research collaborators, strategies for finding research collaborators with their relative success rates, and the outcomes of past and present collaborations. Respondents were further asked to indicate their history and frequency of collaborating with other LIS professionals. Demographic questions, including professional status, years as a librarian, number of libraries at which they have worked, age, ethnicity, and gender were also posed (see appendix for questionnaire). Approval from the San José State University Institutional Review Board was sought and granted (Tracking Number: F18065).

The survey questionnaire was distributed to librarians from June through July 2018. It was shared via local and regional listservs (SJSU library faculty, San Francisco Bay Area Library and Information Network, California Academic Research Libraries, California Library Association, and Northern California Nevada Medical Library Group), ACRL listservs (Arts Section, Health Sciences Interest Group, Residency Interest Group, First-Year Experience, Scholarly Communications, and Science \& Technology Section), and other professional listservs of which the authors were a part (Asian/Pacific American Librarians Association, Chinese American Library Association, Information Literacy Instruction Discussion List, Lifelong Information Literacy Google Group, Emerging Leaders, and New Members Round Table). Additionally, the questionnaire was shared on personal and professional social media and word of mouth. The survey closed on July 31, 2018.

\section{Results}

During the two-month data collection period, 414 responses were received. Of the 414 respondents, 412 proceeded to take the survey, answering some questions, with 277 who completed it in its entirety, resulting in a 67.2 percent completion rate. Among the 365 individuals who identified their current and previous library workplaces, 256 had worked in academic libraries (70.1\%), while 52 had worked in public libraries (14.2\%), 14 in school libraries (3.8\%), and 43 $(11.8 \%)$ in special libraries. There were 265 responses for gender; 32 individuals identified as 
males $(11.9 \%), 233$ as females $(86.6 \%)$, and 4 (1.5\%) who identified as nonbinary. The mean age was 41.4 years $(n=267)$ with a median of 38 years. Respondents' length of time as a professional librarian was a mean of 11.72 years $(n=254)$. The minimum was 0 years, while the maximum was 45 years.

Of the 389 respondents who answered the question about past, current, and future collaborative ventures, 357 or 91.8 percent indicated that they had collaborated, were collaborating, or would be seeking research collaborators; the remaining 32 respondents indicated that they were not interested in seeking research collaborators. Reasons cited for not seeking research collaborators are reported in table 1.

A total of 315 individuals identified the relative importance of various motivational factors for seeking a research collaborator (see table 2). Almost half of the respondents (48\%) rated "Seeking expertise that you lack" as "Very Important"; this deciding motivator was also the top factor when "Important" and "Very Important" ratings were coupled (85\%). Other motivating factors selected by the majority of respondents when coupling Important and Very Important included "Sustaining research interest" (74\%), "Seeking a sounding board" (69\%), "Distributing workload" (68\%), and "Retention, tenure, or promotion" (59\%).

\begin{tabular}{|l|c|c|c|c|c|}
\hline \multicolumn{7}{|c|}{ Motivating Factors for Seeking a Research Collaborator } \\
\hline & $\begin{array}{c}\text { Very } \\
\text { Important }\end{array}$ & Important & $\begin{array}{c}\text { Moderately } \\
\text { Important }\end{array}$ & $\begin{array}{c}\text { Slightly } \\
\text { Important }\end{array}$ & $\begin{array}{c}\text { Not } \\
\text { Important }\end{array}$ \\
\hline Retention, tenure, or promotion & $103(33 \%)$ & $81(26 \%)$ & $54(17 \%)$ & $38(12 \%)$ & $39(12 \%)$ \\
\hline Sustaining research interest & $89(28 \%)$ & $144(46 \%)$ & $55(18 \%)$ & $15(5 \%)$ & $10(3 \%)$ \\
\hline Distributing workload & $66(21 \%)$ & $127(41 \%)$ & $70(22 \%)$ & $26(8 \%)$ & $23(7 \%)$ \\
\hline Seeking expertise that you lack & $151(48 \%)$ & $116(37 \%)$ & $32(10 \%)$ & $12(4 \%)$ & $2(1 \%)$ \\
\hline $\begin{array}{l}\text { Conducting a large study that } \\
\text { involves multiple institutions }\end{array}$ & $52(17 \%)$ & $52(17 \%)$ & $69(22 \%)$ & $41(13 \%)$ & $98(31 \%)$ \\
\hline Seeking a sounding board & $91(29 \%)$ & $126(40 \%)$ & $63(20 \%)$ & $25(8 \%)$ & $10(3 \%)$ \\
\hline Seeking to mentor others & $33(11 \%)$ & $53(17 \%)$ & $65(21 \%)$ & $77(25 \%)$ & $85(27 \%)$ \\
\hline Seeking accountability & $45(14 \%)$ & $103(33 \%)$ & $73(23 \%)$ & $42(13 \%)$ & $51(16 \%)$ \\
\hline Other & $20(47 \%)$ & $13(30 \%)$ & $1(2 \%)$ & $0(0 \%)$ & $9(21 \%)$ \\
\hline
\end{tabular}

\section{Methods for Finding Research Collaborators}

Respondents were asked to select all the strategies that they had or have employed in finding research collaborators from a predetermined list of possibilities and then asked to provide more detail (see figure 1). Among the 312 respondents, places of employment ranked the highest among the methods $(n=298,95.5 \%)$. Respondents indicated convenience, natural 
convergences among work, service, and interests; and familiarity with knowledge, expertise, and skills of colleagues as contributors to initiating a collaborative research relationship.

Being open to collaborations ( $n=245,78.5 \%$ ) was also selected as a highly ranked strategy. This was identified as a passive strategy, as many described that collaborative relationships often stemmed from being approached by another person. Discussing ideas led to greater diversity of thought, which often organically led to considering collaborations. Being open to collaborations would be a necessary precondition to sharing ideas, data, and ultimately the credit that resulted from any research collaborations.

The selection of seeking research collaborators at conferences and other meetings $(n=216$, $69.2 \%$ ) was ranked third among the listed strategies. Respondents indicated that conferences and meetings enabled people to self-partition into groups based on specialization, job function, and pedagogical, research, or professional interests. Furthermore, the regularity of these meetings grounded discussions of research collaboration within timely thematic contexts.

More than a quarter of the respondents used the strategy of contacting authors whose work they had read $(n=88,28.2 \%)$. Respondents noted that authors generally follow up on any queries that involve their research, including new lines of inquiry and employing different methodologies.

Using social media was a strategy employed by 54 respondents $(17.3 \%)$ of the respondent population. Topic currency, calls for proposals, and following up via social media after professional meetings were obvious benefits.

Finding a collaborator through someone I know was selected by 54 (17.3\%) respondents. Referrals from friends, library school instructors, fellow alumni, and colleagues were noted as potential avenues for finding research collaborators or those with rare or needed skill sets.

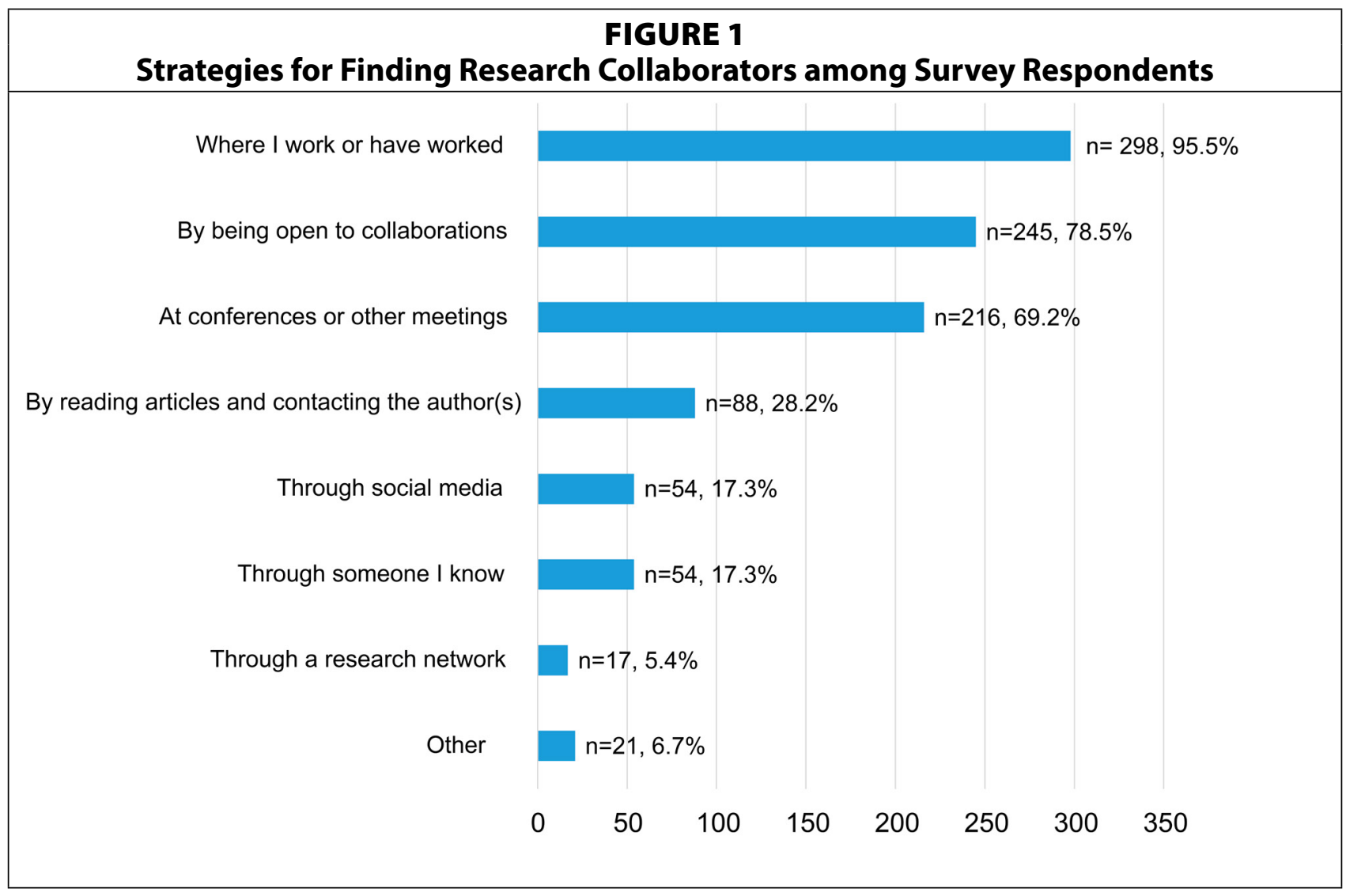


Least selected from the author-provided, prepopulated selections was the use of research networks for finding research collaborators $(\mathrm{n}=17,5.4 \%)$, though respondents identified this as yet another way to find like-minded researchers with the ability to set alerts for new author or topic developments.

Respondents were also encouraged to provide other strategies for finding research collaborators through a free-text, "Other" option. Twenty-one (6.7\%) respondents indicated that professional associations, committee work, listservs, participation in cohort-based programs (such as Immersion or Institute for Research Design in Libraries), alumni networks, and consortia were also venues they have used or plan on using to find research collaborators.

\section{Success Rates among Collaboration Strategies}

Survey respondents were also asked to provide relative success rates to their collaboration strategies by choosing from among three gradations of success as indicated in figure 2. Strategies that were identified as "Extremely Successful" by more than 50 percent of the respondents were places of employment and "Other" (such as association committee work, listservs, alumni networks). Across all other strategies, the option "Moderately Successful" exceeded the number of "Extremely Successful" selections.

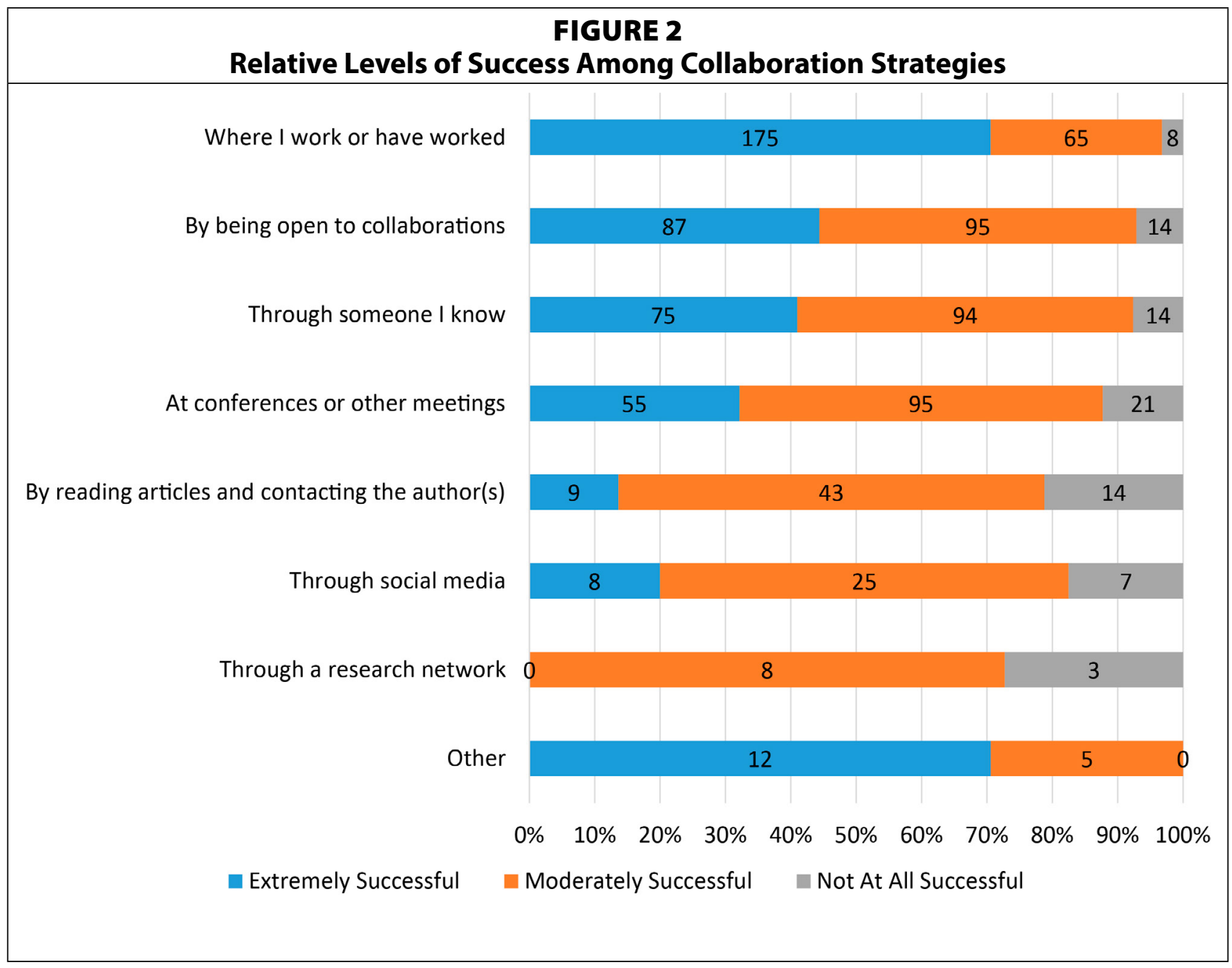




\section{Discussion}

The results of this study report the prevalence of collaboration among librarians, at possibly even higher rates than previously observed in the literature. The survey results indicate that librarians have extremely high participation rates and interest in collaborating, with the majority of respondents (more than $90 \%$ ) indicating that they had sought, are seeking, or will be seeking research collaborators. The degree to which these collaborations will result in coauthored publications remains to be seen, but the findings of this study indicate that librarians and LIS researchers are highly interested in collaborating.

The authors speculate that this interest in collaborating may be a result of the evolving roles of librarians and the needs of library users. Where changing faculty and student needs are impacting traditional librarian work beyond reference, collection development, and teaching, librarians are participating, often in teams with one another or with teaching faculty, in the development of new programs or initiatives that would address these needs and, subsequently, sharing their experiences through co-authored output such as an articles or presentations. Furthermore, the interdisciplinary nature of faculty and librarian research and scholarship has prompted librarians to work in collaboration with individuals within and outside their departments, their campus, and beyond, to share ideas and experiences, gain or provide expertise, and distribute the workload. These elements contribute to a fertile ground for co-authorship.

It is not surprising that the most successful strategies for finding research collaborators are through previous and present places of employment and through interactions at meetings or conferences coupled with the fundamental factor of being open to collaborations. Proximity, shared purpose, and serendipitous interactions can lead to the natural development of research collaborations, as work conducted in teams, engagement in formal and informal discussions at conferences and/or in office hallways, and an understanding of each other's strengths and work styles converge. Furthermore, although the majority of the respondents in this study did not rank social media or research networks as important or successful strategies for finding research collaborators, they can be fruitful places for finding like-minded individuals or topics of potential interest that could develop into a collaborative research project; further investigation is required to understand the impact of these types of tools on the success of research projects.

The relationship between collaborative works and tenure and/or promotion concerns was beyond the scope of this study; however, it bears mentioning that, while tenure and promotion concerns were important among respondents, it is unclear if tenure and promotion considerations impact collaboration and co-authored output. That is, are librarians less likely to seek collaboration when working on projects that pertain to tenure and promotion because co-authorship can be seen as having less value, impact, or effort than single-authored works? The results of this study cannot speak to the perceptions of co-authored research output, but this should be a consideration of future projects involving co-authorship. Regardless, the high level by which respondents to this survey indicated that they had sought, are seeking, or will be seeking a research collaborator demonstrates that LIS research will continue to be collaborative. How collaborative works are interpreted by retention, tenure, and promotion committees is another important but ancillary line of inquiry, as are the potential pressures it would exert on future collaborations. 


\section{Conclusion}

While most studies on research collaborations have used co-authorship on articles or publications as a method for identifying existing research collaborations, this study used a survey questionnaire to examine librarian methods and motivations for finding research collaborators with their corresponding outcomes. The results of this study are limited and should not be used to generalize or characterize all of the motivations behind research collaborations among librarians. The motivations, strategies for seeking research collaborators, and the success rates associated with those strategies, can be very situational or individualistic and based on the needs or experiences of those seeking collaborators; one strategy may be successful for one person and not for another. However, understanding the motivations, strategies, and relative resulting successes for seeking a research collaborator is important for the profession and the organizations that provide programming to support growth and development. The findings can inform institutions or agencies that seek to support, scaffold, and promote collaboration. Furthermore, some outstanding issues of concern for the profession require large collaborative and participatory measures. The observations on the strategies by which librarians seek collaborators can be used to engage members of the profession to meet community-identified goals and initiatives.

The study of co-authorship or collaboration in LIS is multilayered, and there are more outstanding questions. Future areas of inquiry could involve cross-sectional analysis of librarian motivations, strategies for collaboration, and research outcomes by age and time in the profession. Co-authorship studies have primarily investigated journal article publications. Another line of inquiry could pursue the degree of collaboration for presentations and their connection, if any, to future publications. Additionally, it is unclear from this study who librarians are collaborating with -if the collaborators are other librarians and if they are from the same institution. The very question of the value of co-authored works should also be considered, particularly as they are contextualized within the tenure and promotion framework. Answering these questions could continue to help characterize the collaborative publishing environment for LIS researchers and librarians. 


\section{APPENDIX. Survey Questions}

1. Consent: Would you like to continue?

- Yes

- No

2. Have you ever, are you currently, or do you plan on seeking research collaborator(s)? Please note: research collaborators can be new or someone that you've worked with in the past.

- Yes

- No

3. (Displayed if response to $\mathrm{Q} 2$ is " $\mathrm{No}^{\prime}$; respondents are then taken to demographic questions) Please comment on why you have never, are not currently, and will not be seeking research collaborators.

4. Consider your past and present motivations for seeking research collaborator(s). Please indicate how important the following selections were in your decision.

\begin{tabular}{|c|c|c|c|c|c|}
\hline & $\begin{array}{l}\text { Very } \\
\text { Important }\end{array}$ & Important & $\begin{array}{l}\text { Moderately } \\
\text { Important }\end{array}$ & $\begin{array}{l}\text { Slightly } \\
\text { Important }\end{array}$ & $\begin{array}{l}\text { Not } \\
\text { Important }\end{array}$ \\
\hline $\begin{array}{l}\text { Retention, tenure, or } \\
\text { promotion }\end{array}$ & $\mathrm{o}$ & $\mathrm{o}$ & $\mathrm{o}$ & 0 & 0 \\
\hline Sustaining research interest & 0 & 0 & 0 & $\mathrm{o}$ & $\mathrm{o}$ \\
\hline Distributing workload & $\mathrm{o}$ & 0 & 0 & $\mathrm{o}$ & 0 \\
\hline $\begin{array}{l}\text { Seeking expertise that you } \\
\text { lack }\end{array}$ & 0 & 0 & 0 & o & o \\
\hline $\begin{array}{l}\text { Conducting a large study } \\
\text { that involves multiple } \\
\text { institutions }\end{array}$ & 0 & $\mathrm{o}$ & $\mathrm{o}$ & $\mathrm{o}$ & $\mathrm{o}$ \\
\hline Seeking a sounding board & o & 0 & o & o & o \\
\hline Seeking to mentor others & 0 & 0 & 0 & $\mathrm{o}$ & 0 \\
\hline Seeking accountability & 0 & 0 & 0 & 0 & o \\
\hline Other & 0 & 0 & 0 & $\mathrm{o}$ & $\mathrm{o}$ \\
\hline
\end{tabular}


5. I look for or find research collaborator(s)... (check all that apply)

- Where I work or have worked

- At conferences or other meetings

- Through social media (LinkedIn, Twitter, Facebook, etc.)

- Through a research network (ResearchGate, etc.)

- Through someone I know

- By reading articles and contacting the author(s)

- By being open to collaborations

- Other

6. (Only strategies selected in Q5 are displayed for further response):

- Please comment on your strategy of finding research collaborators: "Where you work or have worked"

- Please comment on your strategy of finding research collaborators: "At conferences or other meetings"

- Please comment on your strategy of finding research collaborators: "Through social media"

- Please comment on your strategy of finding research collaborators: "Through a research network"

- Please comment on your strategy of finding research collaborators: “Through someone I know"

- Please comment on your strategy of finding research collaborators: "By reading articles and contacting the author(s)"

- Please comment on your strategy of finding research collaborators: "By being open to collaborations"

- Please comment on your strategy of finding research collaborators: "Other"

7. Please indicate the level of success you have had in finding research collaborators using the following strategies:

\begin{tabular}{|l|c|c|c|}
\hline & $\begin{array}{l}\text { Extremely } \\
\text { Successful }\end{array}$ & $\begin{array}{l}\text { Moderately } \\
\text { Successful }\end{array}$ & $\begin{array}{l}\text { Not at All } \\
\text { Successful }\end{array}$ \\
\hline Where you work or have worked & 0 & 0 & 0 \\
\hline At conferences or other meetings & 0 & 0 & 0 \\
\hline Through social media & 0 & 0 & 0 \\
\hline $\begin{array}{l}\text { Through a research network } \\
\text { (ResearchGate, etc.) }\end{array}$ & 0 & 0 & 0 \\
\hline Through someone I know & 0 & 0 & 0 \\
\hline $\begin{array}{l}\text { By reading articles and contacting the } \\
\text { author(s) }\end{array}$ & 0 & 0 & 0 \\
\hline By being open to collaborations & 0 & 0 & 0 \\
\hline Other & 0 & 0 & 0 \\
\hline
\end{tabular}


8. How many people have you collaborated with on a research project?

9. What were the results of the research collaboration(s)? (Check all that apply)

- Publications

- Presentations

- Works in progress

- Further developed or formulated ideas

- Nothing resulted

10. Have you had multiple research collaborations with the same person?

- Yes

- No

11. Consider the libraries where you work or have worked. Mark your status and rank (check all that apply)

\begin{tabular}{|c|c|c|c|c|c|c|c|c|c|c|c|c|c|}
\hline & \multicolumn{4}{|l|}{ Rank } & \multicolumn{5}{|l|}{ Status } & \multicolumn{2}{|c|}{$\begin{array}{l}\text { Was research or } \\
\text { scholarship a } \\
\text { requirement for } \\
\text { advancement, } \\
\text { tenure, or } \\
\text { promotion? }\end{array}$} & \multicolumn{2}{|c|}{$\begin{array}{l}\text { Did you seek } \\
\text { research } \\
\text { collaborator(s) } \\
\text { when working } \\
\text { at this type of } \\
\text { library? }\end{array}$} \\
\hline & $\begin{array}{l}\text { Assistant } \\
\text { Librarian }\end{array}$ & $\begin{array}{l}\text { Associate } \\
\text { Librarian }\end{array}$ & $\begin{array}{l}\text { Full } \\
\text { Librarian }\end{array}$ & Other & $\begin{array}{l}\text { Tenure } \\
\text { Track }\end{array}$ & \begin{tabular}{|l} 
Non- \\
Tenure \\
Track
\end{tabular} & $\begin{array}{l}\text { Administrative } \\
\text { or Academic } \\
\text { Professional }\end{array}$ & Staff & Other & Yes & No & Yes & No \\
\hline $\begin{array}{l}\text { Academic } \\
\text { Library }\end{array}$ & o & o & 0 & 0 & 0 & 0 & 0 & o & 0 & 0 & 0 & 0 & o \\
\hline $\begin{array}{l}\text { Public } \\
\text { Library }\end{array}$ & o & o & 0 & 0 & 0 & 0 & 0 & 0 & 0 & 0 & 0 & 0 & o \\
\hline $\begin{array}{l}\text { School } \\
\text { Library }\end{array}$ & o & o & o & o & o & 0 & o & o & 0 & 0 & 0 & 0 & o \\
\hline $\begin{array}{l}\text { Special } \\
\text { Library }\end{array}$ & 0 & 0 & o & 0 & 0 & 0 & 0 & 0 & o & 0 & o & 0 & o \\
\hline
\end{tabular}

12. Years as professional librarian

13. Number of libraries you've worked at

14. What is your age? 
15. What is your ethnicity, origin, or race (select all that apply)

- White

- Hispanic or Latino

- Black or African American

- Native American or American Indian

- Asian/Pacific Islander

- Other

16. What is your gender?

- Male

- Female

- Nonbinary

\section{Notes}

1. Sally Jo Cunningham and S.M. Dillon, "Authorship Patterns in Information Systems," Scientometrics 39, no. 1 (1997): 25; Dorte Henriksen, “The Rise in Co-Authorship in the Social Sciences (1980-2013)," Scientometrics 107 (2016): 471.

2. Gloria S. Cline, "College \& Research Libraries: Its First Forty Years," College \& Research Libraries 43, no. 3 (1982): 215.

3. James L. Terry, "Authorship in College \& Research Libraries Revisited: Gender, Institutional Affiliation, Collaboration," College \& Research Libraries 57, no. 4 (1996): 380-81.

4. Alice Harrison Bahr and Mickey Zemon, "Collaborative Authorship in the Journal Literature: Perspectives for Librarians Who Wish to Publish," College \& Research Libraries 61, no. 5 (2000): 414.

5. Lili Luo and Margaret McKinney, "JAL in the Past Decade: A Comprehensive Analysis of Academic Library Research," Journal of Academic Librarianship 41 (2015): 125.

6. Ann C. Weller, Julie M. Hurd, and Stephen E. Wiberley Jr., "Publication Patterns of U.S. Academic Librarians from 1993 to 1997," College \& Research Libraries 60, no. 4 (1999): 356-57.

7. Stephen E. Wiberley Jr., Julie M. Hurd, and Ann C. Weller, "Publication Patterns of U.S. Academic Librarians from 1998 to 2002," College \& Research Libraries 67, no. 3 (2006): 208.

8. Deborah D. Blecic et al., "Publication Patterns of U.S. Academic Librarians and Libraries from 2003 to 2012," College E Research Libraries 78, no. 4 (2017): 447-48.

9. Blecic et al., "Publication Patterns of U.S. Academic Librarians and Libraries from 2003 to 2012."

10. Richard L. Hart, "Collaborative Publication by University Librarians: An Exploratory Study," Journal of Academic Librarianship 26, no. 2 (2000): 96-97.

11. Hart, "Collaborative Publication by University Librarians."

12. Richard L. Hart, "Co-authorship in the Academic Library Literature: A Survey of Attitudes and Behavior," Journal of Academic Librarianship 26, no. 5 (2000): 341-42.

13. Hart, "Co-authorship in the Academic Library Literature."

14. Hart, "Collaborative Publication by University Librarians," 96.

15. Hart, "Co-authorship in the Academic Library Literature," 341.

16. John M. Budd and Charles A. Seavey, "Characteristics of Journal Authorship by Academic Librarians," College \& Research Libraries 51, no. 5 (1990): 13-14; Weller, Hurd, and Wiberley, "Publication Patterns of U.S. Academic Librarians from 1993 to 1997," 357-58.

17. Peter Hernon, Allen Smith, and Mary Bailey Croxen, "Publication in College \& Research Libraries: Accepted, Rejected and Published Papers, 1980-1991," College \& Research Libraries 54, no. 4 (1993): 312.

18. Deborah Beaver, "Reflections on Scientific Collaboration (and its Study): Past, Present and Future," Scientometrics 52 (2001): 373.

19. David W. Payton, "Discovering Collaborators by Analyzing Trails Through an Information Space," AAAI Technical Report FS-98-01 (1998); Sarah Cohen and Lior Ebel, "Recommending Collaborators Using Keywords," International World Wide Web Conference Committee (IW3C2 2013 Companion, May 13-17, 2013, Rio de Janeiro, Brazil). 